\title{
The prevalence of multimorbidity in primary care: a comparison of two definitions of multimorbidity with two different lists of chronic conditions in Singapore
}

\author{
Eng Sing Lee ${ }^{1 *}\left(\mathbb{D}\right.$, Poay Sian Sabrina Lee ${ }^{1}$, Ying Xie ${ }^{1}$, Bridget L. Ryan ${ }^{2,3}$, Martin Fortin ${ }^{4}$ and Moira Stewart ${ }^{2,3}$
}

\begin{abstract}
Background: The prevalence of multimorbidity varies widely due to the lack of consensus in defining multimorbidity. This study aimed to measure the prevalence of multimorbidity in a primary care setting using two definitions of multimorbidity with two different lists of chronic conditions.

Methods: We conducted a cross-sectional study of 787,446 patients, aged 0 to 99 years, who consulted a family physician between July 2015 to June 2016. Multimorbidity was defined as 'two or more' (MM2+) or 'three or more' (MM3+) chronic conditions using the Fortin list and Chronic Disease Management Program (CDMP) list of chronic conditions. Crude and standardised prevalence rates were reported, and the corresponding age, sex or ethnic-stratified standardised prevalence rates were adjusted to the local population census.

Results: The number of patients with multimorbidity increased with age. Age-sex-ethnicity standardised prevalence rates of multimorbidity using MM2+ and MM3 + for Fortin list (25.9, 17.2\%) were higher than those for CDMP list (22.0\%; 12.4\%). Sex-stratified, age-ethnicity standardised prevalence rates for MM2+ and MM3+ were consistently higher in males compared to females for both lists. Chinese and Indians have the highest standardised prevalence rates among the four ethnicities using $\mathrm{MM} 2+$ and $\mathrm{MM} 3+$ respectively.

Conclusions: MM3 + was better at identifying a smaller number of patients with multimorbidity requiring higher needs compared to MM2+. Using the Fortin list seemed more appropriate than the CDMP list because the chronic conditions in Fortin's list were more commonly seen in primary care. A consistent definition of multimorbidity will help researchers and clinicians to understand the epidemiology of multimorbidity better.
\end{abstract}

Keywords: Multimorbidity, Prevalence, Age, Sex, Ethnicity, Primary care

\footnotetext{
* Correspondence: eng_sing_lee@nhgp.com.sg

${ }^{1}$ Clinical Research Unit, National Healthcare Group Polyclinics, Singapore, Singapore

Full list of author information is available at the end of the article
}

(c) The Author(s). 2021 Open Access This article is licensed under a Creative Commons Attribution 4.0 International License, which permits use, sharing, adaptation, distribution and reproduction in any medium or format, as long as you give appropriate credit to the original author(s) and the source, provide a link to the Creative Commons licence, and indicate if changes were made. The images or other third party material in this article are included in the article's Creative Commons licence, unless indicated otherwise in a credit line to the material. If material is not included in the article's Creative Commons licence and your intended use is not permitted by statutory regulation or exceeds the permitted use, you will need to obtain permission directly from the copyright holder. To view a copy of this licence, visit http://creativecommons.org/licenses/by/4.0/. The Creative Commons Public Domain Dedication waiver (http://creativecommons.org/publicdomain/zero/1.0/) applies to the data made available in this article, unless otherwise stated in a credit line to the data. 


\section{Background}

By 2050, the world's population aged 60 years and older is estimated to be 2 billion people [1]. Not only does a longer life expectancy increase the chance of developing one chronic condition, but the possibility of having multiple chronic conditions (i.e., multimorbidity) also increases. Multimorbidity poses a major challenge to the healthcare systems as increased number of people have multimorbidity with age [1].

Estimates for the prevalence of multimorbidity in primary care vary widely (12.9 to $95.1 \%)$ due to the inconsistencies in the definition of multimorbidity [2]. The measurement of multimorbidity based on counting number of chronic conditions depends on five components that are closely related to the definition of the entity: a) the types of conditions selected to form the multimorbidity list; b) the total number of conditions considered in the multimorbidity list; c) the cut-off threshold for the number of chronic conditions used to define multimorbidity; d) the data sources of the conditions; and e) the reference population being measured [3-5]. The lack of reporting or consensus on the five components have made comparisons between prevalence rates found in different studies difficult, preventing reliable estimations of disease burden and hinder resource distribution for effective disease management. Our recent work has proposed that an ideal operational definition of multimorbidity should comprise at least 12 chronic diseases, each with high burden and clinically relevant to the particular healthcare setting of interest [6].

The types of conditions, number of conditions and the cut-off thresholds used are the more contentious components. There are no fixed conditions used for the multimorbidity list; the number of conditions used in multimorbidity prevalence studies range from 4 to 147 [7]. Fortin et al. suggested a list of 20 conditions for multimorbidity that were prevalent or had high patient impact [8]. However, a different list of 20 conditions under the Chronic Disease Management Programme (CDMP) list from the Ministry of Health of Singapore $(\mathrm{MOH})$ identified for government subsidy locally may also be suitable [9]. Although the World Health Organization defines multimorbidity as the co-occurrence of two or more chronic conditions in an individual [10], Fortin et al. suggested that studies should include two operational definitions of multimorbidity, i.e., for two or more chronic conditions and three or more chronic conditions [3].

This study sought to examine the prevalence of multimorbidity in the Singapore primary care population using electronic medical records. The objectives of this study were to: (1) describe the epidemiology of chronic conditions using two lists of conditions (International list: Fortin and Local list: CDMP) to define multimorbidity; (2) determine the crude and standardised prevalence rates of multimorbidity based on the two different lists of chronic conditions with two operational definitions of multimorbidity based on the two commonly reported cut-off thresholds $(2+$ and $3+$ chronic conditions); and (3) determine the differences in the standardised prevalence rates among the different age, sex and ethnic groups.

\section{Methods}

This was a cross-sectional study of patients aged 0 to 99 years who consulted a family physician at any of the nine National Healthcare Group Polyclinics (NHGP) in Singapore between 1st July 2015 and 30th June 2016 and who had an ICD-10 (International Classification of Diseases, Tenth Revision) diagnosis code. A polyclinic is a government-funded primary care centre that offers a one-stop centre including chronic disease management [11]. Data were obtained from the electronic medical records. The denominator was all patients who had consulted a family physician at least once in the stipulated time frame.

The numerator was the number of patients that had multimorbidity. The numerator was chosen with the following considerations. Firstly, we adopted the definition of chronicity of a disease as lasting at least six months, having a documented pattern of recurrence or deterioration, and having an impact on an individual's quality of life [12]. Secondly, we used two different lists of chronic conditions to measure multimorbidity - a local list (CDMP list - Additional file 1) and an international list (Fortin list - Additional file 2). Thirdly, we used two cut-off thresholds - 'two or more' chronic conditions (MM2+) and 'three or more' chronic conditions (MM3+ ). As such, there were four numerators: the operational definition of $\mathrm{MM} 2+$ using the CDMP list (CDMP MM2+), MM3+ using the CDMP list (CDMP MM3+), MM2+ using the Fortin list (Fortin MM2+), and MM3+ using the Fortin list (Fortin MM3+).

We matched all the NHGP ICD-10 diagnosis codes classified as a chronic condition to both lists because the CDMP list was based on diagnoses stipulated on the $\mathrm{MOH}$ website and the Fortin list was based on ICPC-2 (International Classification of Primary Care - 2nd edition). Four NHGP senior family physicians were consulted on the appropriateness of the matched ICD-10 codes to the two lists. They unanimously agreed on the appropriateness of the matching of all CDMP conditions to the ICD-10 diagnoses but found only 19 of the 20 Fortin conditions to be appropriately matched to the ICD-10 diagnosis codes. 'Back pain' in the Fortin list was not matched with the NHGP ICD-10 codes because the condition was usually coded as an acute rather than a chronic condition in NHGP. Ultimately, there were 26 ICD-10 codes and 39 ICD-10 codes matched to the 
CDMP and Fortin lists respectively (described in Additional file 1 and Additional file 2).

IBM SPSS version 21 and Microsoft Office Excel 2016 were used for all statistical calculations and analyses. We described the means for continuous variables with their respective standard deviations and proportions with their respective confidence intervals where appropriate. For corresponding age/sex/ethnic stratified standardised prevalence rates, we provided the weighted average of prevalence rate where the weights were the proportions of persons according to the 2016 Singapore Population $[13,14]$. Confidence intervals of $95 \%$ were calculated using the Poisson approximation around the standardised rates among the different age, sex and ethnic groups. We considered no overlap of the $95 \%$ confidence intervals for the standardised prevalence rates among the different groups as statistically significant. For multiple comparisons, Bonferroni adjustment was applied.

\section{Results}

\section{Epidemiology of chronic conditions using two lists of conditions (CDMP and Fortin)}

This study included 787,446 unique patients from nine NHG Polyclinics. Table 1 shows the demographic characteristics of the study population compared to the national Singaporean population. The majority of the patients in this study were in the 45-64 years age group (32.0\%). The Chinese formed the majority of the study population (68.2\%), followed by Malays (16.2\%), Indians $(10.0 \%)$, and Others $(5.6 \%)$. The mean age of Chinese patients was 47.1 years $( \pm 23.3)$ while the mean ages of Malay, Indian and Other patients were lower at 35.1 years $( \pm 22.1), \quad 39.7$ years $( \pm 21.1)$ and $37.1 \quad( \pm 19.1)$ respectively. There were slightly more females (50.9\%) than males (49.1\%). The mean age of the female patients was older at $45.3( \pm 23.2)$ years compared to the male patients at $42.4( \pm 23.2)$ years.

The mean number of chronic conditions increased with age. In Table 1, we observed that patients under 45 years old had fewer chronic conditions for both lists. On the other hand, the oldest group aged 65 years and above had the highest mean number of chronic conditions; mean of $2.4( \pm 1.5)$ and $3.0( \pm 1.8)$ chronic conditions when the CDMP and Fortin lists were used respectively. The Chinese had the highest mean number of chronic conditions (CDMP: 1.1, Fortin: 1.4), followed by the Indians (CDMP: 0.9, Fortin: 1.2), then Malays (CDMP: 0.8, Fortin: 1.0), and lastly Others (CDMP: 0.6, Fortin: 0.8 ).

Table 2 reports the patient count and crude prevalence rates of the individual chronic conditions for both lists. The three most prevalent conditions in both lists were 'hyperlipidaemia', 'hypertension' and 'diabetes', with prevalence rates above $10.0 \%$. Additionally, the Fortin list also identified a fourth condition, 'Arthritis \&/or Rheumatoid Arthritis', which also had a prevalence rate above $10.0 \%$. There were nine chronic conditions with prevalence rates above $1.0 \%$ in the CDMP list compared to 16 chronic conditions in the Fortin list.

Figures 1 and 2 report the percentage of patients with chronic conditions based on the standardized prevalence rate for sex and ethnicity, stratified by age. Both figures showed that the proportion of patients with chronic conditions increased with the advancement of age. The CDMP list (Fig. 1) showed that $50 \%$ of the population in primary care had one chronic condition in their late 40s, two chronic conditions in their late $50 \mathrm{~s}$ and three

Table 1 Demographic characteristics of the patients in the study $(N=787,446)$

\begin{tabular}{|c|c|c|c|c|c|c|}
\hline & Number of patients $(\mathrm{N})$ & Percentage (\%) & National Proportion 2016 (\%) & $\begin{array}{l}\text { Age (years) } \\
\text { Mean }\left(S^{\mathrm{b}}\right)\end{array}$ & $\begin{array}{l}\text { Number of CDMP } \\
\text { Conditions, } \\
\text { Mean }\left(S^{b}\right)\end{array}$ & $\begin{array}{l}\text { Number of Fortin } \\
\text { Conditions, } \\
\text { Mean (SD })\end{array}$ \\
\hline \multicolumn{7}{|l|}{ AGE } \\
\hline $0-24$ years & 201,839 & 25.6 & 26.9 & $12.9(8.1)$ & $0.0(0.2)$ & $0.1(0.3)$ \\
\hline $25-44$ years & 165,212 & 21.0 & 30.5 & $34.0(6.0)$ & $0.2(0.6)$ & $0.4(0.8)$ \\
\hline 45-64 years & 252,206 & 32.0 & 29.3 & $55.4(5.5)$ & $1.3(1.3)$ & $1.7(1.6)$ \\
\hline $65-99$ years & 168,189 & 21.4 & 13.3 & $73.5(7.0)$ & $2.4(1.5)$ & $3.0(1.8)$ \\
\hline \multicolumn{7}{|l|}{ ETHNICITY } \\
\hline Chinese & 537,234 & 68.2 & 74.3 & $47.1(23.3)$ & $1.1(1.4)$ & $1.4(1.7)$ \\
\hline Malay & 127,501 & 16.2 & 13.4 & $35.1(22.1)$ & $0.8(1.3)$ & $1.0(1.6)$ \\
\hline Indian & 78,452 & 10.0 & 9.1 & 39.7 (21.1) & $0.9(1.4)$ & $1.2(1.8)$ \\
\hline Others & 44,259 & 5.6 & 3.2 & 37.1 (19.1) & $0.6(1.1)$ & $0.8(1.4)$ \\
\hline \multicolumn{7}{|l|}{ SEX } \\
\hline Female & 400,965 & 50.9 & 51.2 & $45.3(23.2)$ & $1.0(1.3)$ & $1.3(1.7)$ \\
\hline Male & 386,481 & 49.1 & 48.8 & $42.4(23.2)$ & $1.0(1.4)$ & $1.3(1.7)$ \\
\hline
\end{tabular}

${ }^{a}$ CDMP Chronic Disease Management Programme, ${ }^{\text {b } S D ~ S t a n d a r d ~ d e v i a t i o n ~}$ 
Table 2 Crude prevalence rates of single chronic conditions from CDMP and Fortin lists

\begin{tabular}{|c|c|c|c|c|c|c|}
\hline Rank & CDMP $^{\mathrm{a}}$ Conditions & Patient Count & $\%$ & Fortin Conditions & Patient Count & $\%$ \\
\hline 1 & Hyperlipidaemia & 257,114 & 32.7 & Hyperlipidaemia & 257,114 & 32.7 \\
\hline 2 & Hypertension & 221,760 & 28.2 & Hypertension & 221,760 & 28.2 \\
\hline 3 & Diabetes & 125,058 & 15.9 & Diabetes & 124,954 & 15.9 \\
\hline 4 & Ischaemic Heart Disease & 36,401 & 4.6 & Arthritis \&/or Rheumatoid arthritis & 100,838 & 12.8 \\
\hline 5 & Asthma & 28,778 & 3.7 & Obesity & 48,893 & 6.2 \\
\hline 6 & Chronic Kidney Disease & 21,638 & 2.7 & $\begin{array}{l}\text { Cardiovascular disease (Angina, Myocardial infarction, } \\
\text { Atrial fibrillation, poor circulation of lower limbs) }\end{array}$ & 43,559 & 5.5 \\
\hline 7 & Stroke & 19,808 & 2.5 & Asthma, COPD ${ }^{b}$, or Chronic bronchitis & 32,611 & 4.1 \\
\hline 8 & Osteoarthritis & 18,378 & 2.3 & Chronic hepatitis & 25,918 & 3.3 \\
\hline 9 & Benign Prostate Hypertrophy & 13,031 & 1.7 & Stroke and Transient Ischaemic Attack & 23,628 & 3.0 \\
\hline 10 & Osteoporosis & 7283 & 0.9 & Stomach problem (reflux, heartburn, or gastric ulcer) & 22,233 & 2.8 \\
\hline 11 & Anxiety & 6085 & 0.8 & Kidney disease or failure & 22,221 & 2.8 \\
\hline 12 & $\begin{array}{l}\text { Chronic Obstructive Pulmonary } \\
\text { Disease (COPD) }\end{array}$ & 5080 & 0.6 & Thyroid disorder & 20,781 & 2.6 \\
\hline 13 & Dementia & 3571 & 0.5 & Heart failure (including valve problem or replacement) & 20,538 & 2.6 \\
\hline 14 & Schizophrenia & 2889 & 0.4 & Depression or anxiety & 14,910 & 1.9 \\
\hline 15 & Epilepsy & 2734 & 0.3 & Chronic urinary problem & 13,031 & 1.7 \\
\hline 16 & Rheumatoid Arthritis & 2010 & 0.3 & Any Cancer in the last 5 years & 7940 & 1.0 \\
\hline 17 & Parkinson's & 1900 & 0.2 & Osteoporosis & 7283 & 0.9 \\
\hline 18 & Major Depression & 1700 & 0.2 & Dementia or Alzheimer's disease & 3571 & 0.5 \\
\hline 19 & Psoriasis & 651 & 0.1 & Colon problem (irritable bowel) & 1571 & 0.2 \\
\hline 20 & Bipolar Disorder & 51 & 0.0 & & & \\
\hline
\end{tabular}

${ }^{a}$ CDMP Chronic Disease Management Programme, ${ }^{b}$ COPD Chronic obstructive pulmonary disease

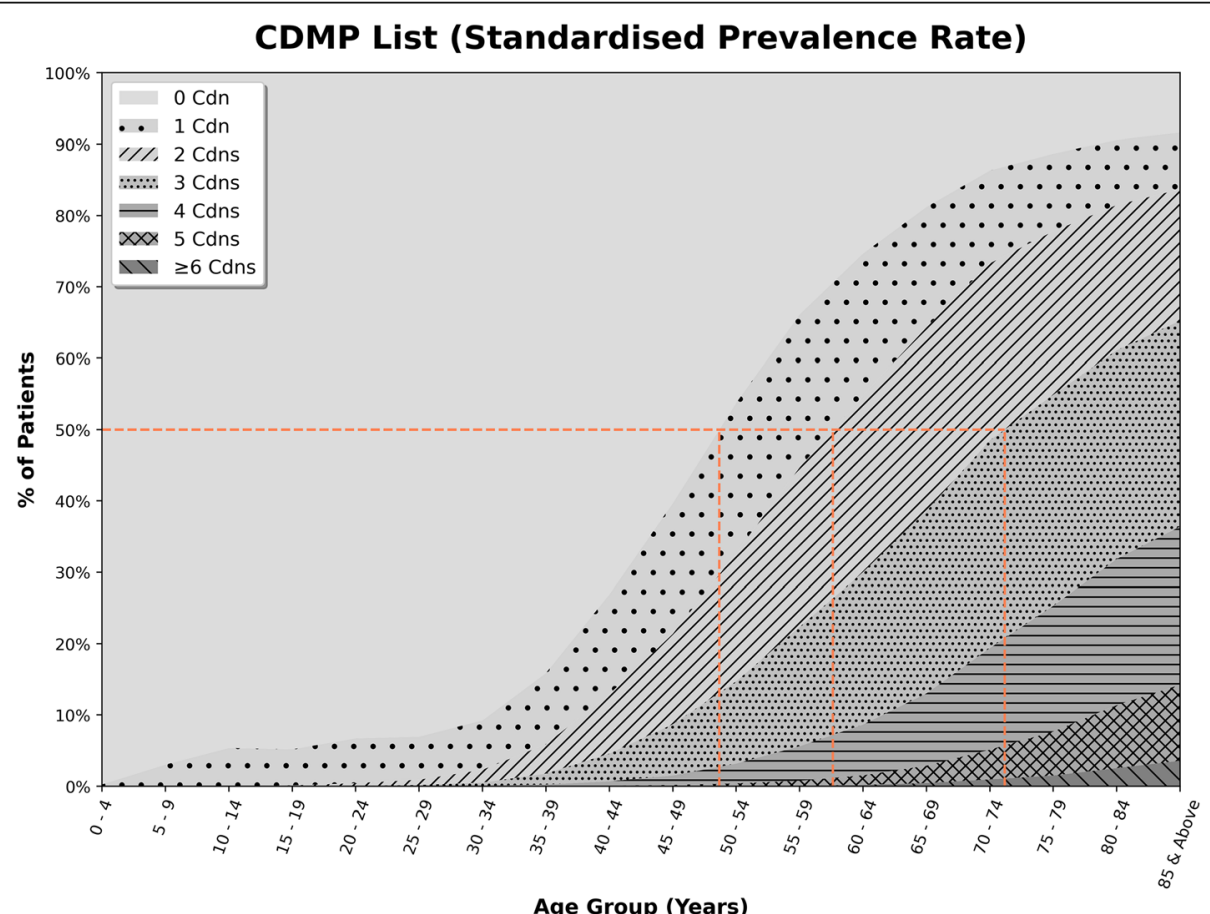

Fig. 1 Number of chronic conditions by age-group (CDMP list) 


\section{Fortin List (Standardised Prevalence Rate)}

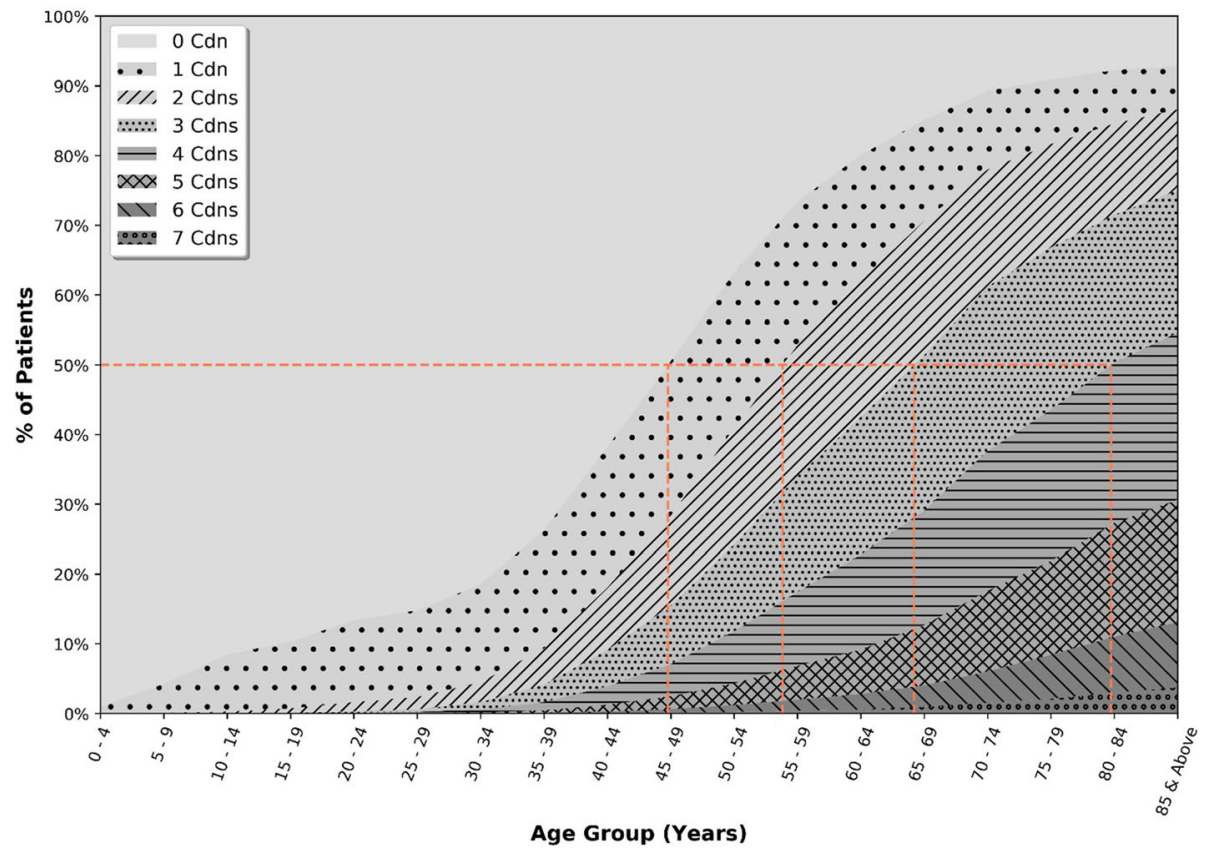

*8-19 conditions are omitted as the data counts are negligible in comparison to 0-7 conditions

Fig. 2 Number of chronic conditions by age-group (Fortin list)

chronic conditions in their early 70s. The Fortin list (Fig. 2) showed that $50 \%$ of the population in primary care had chronic condition(s) at earlier ages i.e., one chronic condition in their early 40s, two chronic conditions in their early 50s, three chronic conditions in their early $60 \mathrm{~s}$, and four chronic conditions in their late $70 \mathrm{~s}$.

\section{Prevalence rates of multimorbidity based on two} different lists with two operational definitions

The crude prevalence rates of multimorbidity in descending order were MM2+ Fortin at 33.9\%, MM2+ CDMP at 29.7\%, MM3 + Fortin at 23.7\%, and MM3+ CDMP at $17.7 \%$. The standardised prevalence rates of multimorbidity were of the same order but with a smaller magnitude after adjusting for age, ethnicity and sex. They were 25.9\% (CI 25.8, 26.0), 22.0\% (CI 21.9,
22.1), 17.2\% (CI 17.2, 17.3), and $12.4 \%$ (CI 12.3, 12.5) respectively.

Differences in the standardized prevalence rates among the different age, sex and ethnic groups

The standardised prevalence rates of multimorbidity increased with age as shown in Table 3. There were statistically significant differences among the standardised prevalence rates of multimorbidity among all four age groups.

The standardised prevalence rates of multimorbidity were higher for male patients when compared to female patients for both the CDMP and Fortin lists using both definitions of MM2+ and MM3+ (Table 4). The differences were statistically significant.

Using the CDMP list and the MM2+ definition, the standardised prevalence rates of multimorbidity for the

Table 3 Standardized Prevalence Rates of Multimorbidity - prevalence rates are standardised for sex and ethnicity

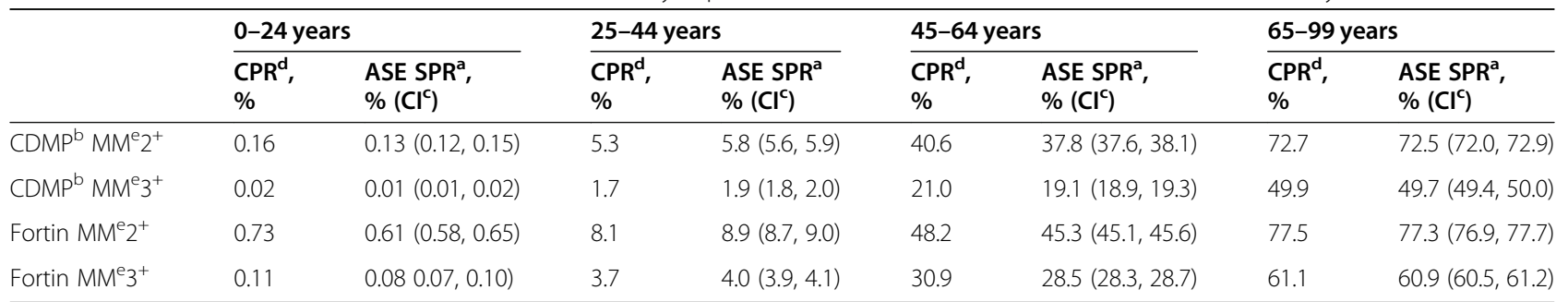

${ }^{\mathrm{a}}$ ASE SPR Age-stratified, sex-and-ethnicity standardized prevalence rate, ${ }^{\mathrm{b}} \mathrm{CDMP}$ Chronic Disease Management Programme, ${ }^{\mathrm{C}} \mathrm{Cl}$ Confidence interval, ${ }^{\mathrm{d}} \mathrm{CPR}$ Crude prevalence rate, ${ }^{\mathrm{e}} \mathrm{MM}$ Multimorbidity 
Table 4 Standardized Prevalence Rates - prevalence rates are standardised for age and ethnicity

\begin{tabular}{|c|c|c|c|c|}
\hline & \multicolumn{2}{|c|}{ Female } & \multicolumn{2}{|l|}{ Male } \\
\hline & $\begin{array}{l}\mathrm{CPR}^{\mathrm{d}}, \\
\%\end{array}$ & $\begin{array}{l}\text { SAE SPR }{ }^{a}, \\
\%\left(C^{1}\right)\end{array}$ & $\begin{array}{l}\mathrm{CPR}^{\mathrm{d}}, \\
\%\end{array}$ & $\begin{array}{l}\text { SAE SPR }{ }^{a}, \\
\%\left(C^{\prime}\right)\end{array}$ \\
\hline $\mathrm{CDMP}^{\mathrm{b}} \mathrm{MM}^{\mathrm{e}} 2^{+}$ & 29.4 & $20.5(20.4,20.6)$ & 29.9 & $23.5(23.4,23.7)$ \\
\hline $\mathrm{CDMP}^{\mathrm{b}} \mathrm{MM}^{\mathrm{e}} 3^{+}$ & 16.5 & $11.2(11.1,11.3)$ & 18.7 & $13.7(13.6,13.8)$ \\
\hline Fortin $\mathrm{MM}^{\mathrm{e}} 2^{+}$ & 34.6 & $25.0(24.8,25.1)$ & 33.2 & $26.8(26.7,27.0)$ \\
\hline Fortin $\mathrm{MM}^{\mathrm{e}} 3^{+}$ & 24.0 & $16.5(16.4,16.6)$ & 23.4 & $18.0(17.9,18.1)$ \\
\hline
\end{tabular}

a SAE SPR Sex-stratified, age-and-ethnicity standardized prevalence rate, ${ }^{\mathrm{b}}$ CDMP Chronic Disease Management Programme, ${ }^{c} \mathrm{Cl}$ Confidence interval, ${ }^{d}$ $C P R$ Crude prevalence rate, ${ }^{\mathrm{e}} \mathrm{MM}$ Multimorbidity

different ethnic groups in descending order were Chinese, Indians, Malays and Others (Table 5). For the MM3+ definition, the Indian ethnic group had the highest standardised prevalence rate of multimorbidity followed by Malays, Chinese, and the Others. The ranking order of the ethnic groups based on the standardized prevalence rates of the Fortin list was consistent for both MM2+ and MM3+ definitions. They were Chinese, followed by Indians, then Malays and Others. All the differences for both lists were statistically significant except for the standardised prevalence rates for Chinese $(12.5 \%$ CI 12.4, 12.6) and Malays (12.6\% CI 12.4, 12.8) using the CDMP MM3+ definition, and the standardised prevalence rates for Chinese $(17.5 \%$ CI 17.4, 17.6) and Indians (17.5\% CI 17.3, 17.8) using the Fortin MM3+ definition.

\section{Discussion}

\section{Summary of main findings}

The crude prevalence rates of multimorbidity across all age groups ranged from 17.7 to $33.9 \%$. The standardised prevalence rate ranged from $12.4 \%$ (CI 12.3, 12.5) to 25.9\% (CI 25.8, 26.0) with MM3 + CDMP having the lowest standardised prevalence rate and $\mathrm{MM} 2+$ Fortin having the highest. Our study showed that using different definitions and lists of conditions for multimorbidity measurement resulted in different prevalence rates which were statistically different from each other when we adjusted for age, sex, and ethnicity for the same population. Whichever lists that we used, we found that prevalence rates of multimorbidity increased with age, and males had a statistically significantly higher prevalence rate of multimorbidity compared to females. There were also differences in prevalence rates of multimorbidity in the different ethnic groups, but the differences were dependent on operational definitions of multimorbidity.

\section{Comparison with existing literature}

Our standardised prevalence rates using MM2+ $(22.0 \%$ for CDMP; $25.9 \%$ for Fortin) were higher than that of MM3+ (12.4\% for CDMP; $17.2 \%$ for Fortin). This is consistent with another study that reported the agestandardised prevalence rate of two or more chronic conditions to be higher when compared with three or more chronic conditions [15] (26.5 and 10.2\% respectively using Canada's 1991 population as the standard population).

There were six multimorbidity prevalence studies conducted using the definition of $\mathrm{MM} 2+$ in Singapore. None of the studies described clearly how the chronic conditions on the lists used were selected (the number of conditions ranged from 8 to 48), and none of the studies standardised their prevalence rate to a reference population. The crude prevalence rates of multimorbidity ranged from 16.3 to $89.4 \%$ for different age groups [16-21]. We compared the findings from Quah et al. [19] which targeted older adults age 65 years and over as it was the only study that was conducted in the primary care setting. The mean age and standard deviation of the participants was $73.9( \pm 6.5)$ years old which was comparable to the mean age of this study which was 73.5 ( \pm 7.0) years old (Table 1). The authors reported that the prevalence of multimorbidity was $89.4 \%$ which was higher than that found in this study - MM2+ CDMP was $72.7 \%$ and MM2+ Fortin was $77.5 \%$ (Table 3). This difference could be attributed to the difference in the conditions used to define multimorbidity and the data collection methods. Quah et al. [19] used intervieweradministered questionnaire while this study used electronic medical records. Several studies have reported variable concordance rates between questionnaire and electronic medical records [22, 23].

Table 5 Standardized Prevalence Rates - prevalence rates are standardised for age and sex

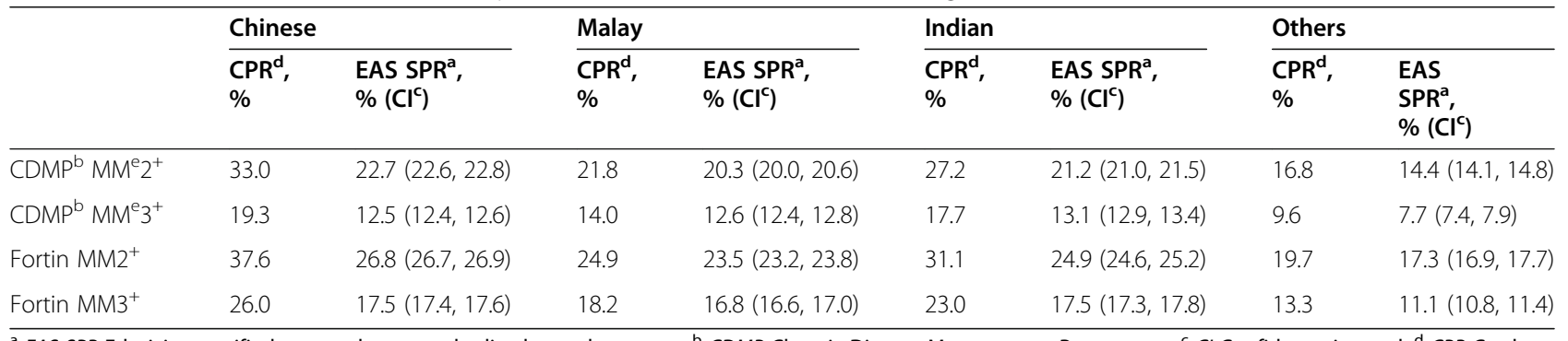

${ }^{\mathrm{a}}$ EAS SPR Ethnicity-stratified, age-and-sex standardized prevalence rate, ${ }^{\mathrm{b}} \mathrm{CDMP}$ Chronic Disease Management Programme, ${ }^{\mathrm{c}} \mathrm{Cl}$ Confidence interval, ${ }^{\mathrm{d}} \mathrm{CPR}$ Crude prevalence rate, ${ }^{\text {e }} M M$ Multimorbidity 
Our study found a higher prevalence rate of multimorbidity in males than females. However, the literature reported inconsistent differences in the prevalence rates between the sexes. These differences could be associated with the population source and the types of conditions studied. For example, Fortin et al. reported that more females than males were found with multimorbidity in the general population whereas the contrary was found in the practice-based population [4]. Schafer et al. reported females seemed to be more vulnerable to anxiety, depression, somatoform disorders, and pain-related morbidity while males appeared to be more vulnerable to cardiovascular and metabolic diseases [24].

Our study was based on a practice-based population; the distribution of single chronic conditions by prevalence rates $(>10 \%)$ in both multimorbidity lists were dominated by three cardiometabolic conditions (e.g. hyperlipidaemia, hypertension, diabetes) and one degenerative-related condition e.g., arthritis and/or rheumatoid arthritis. Psychological disorders (e.g., depression or anxiety) accounted for less than $2 \%$ of all chronic conditions (Table 2). The low prevalence of psychological disorders in our study contrasted with other prevalence studies. Within the Canadian population, Ryan et al. [25] found that mood disorders were among the five most prevalent conditions in every age group. Within the Portuguese population, Prazeres et al. [26] found that depressive disorder was the third most prevalent condition. A likely reason for the low prevalence of psychological disorder was the social stigma associated with these conditions resulting in the decreased help-seeking behaviour by the local population [27].

Singapore is a multi-ethnic country which comprises of three main ethnic groups. However, the impact of ethnicity on prevalence of multimorbidity remains relatively unexplored. One study by Picco et al. reported that the crude prevalence rate of multimorbidity in Indians was higher than the Chinese and Malay [17]. This differed from our findings where the standardized prevalence rate of multimorbidity using the same cut-off threshold of two or more conditions was the highest in Chinese followed by Indians and Malay. Further studies to explore the patterns of multimorbidity among the different ethnic groups should be done.

\section{Comparison between $\mathrm{MM} 2+$ and $\mathrm{MM} 3+$ cut-off thresholds, and CDMP and Fortin lists}

Using MM3+ as the cut-off identified a smaller number of patients with higher needs compared to MM2+ which was consistent for both lists and also consistent with the findings from a systematic review [3]. The Fortin list generated a higher prevalence rate of multimorbidity compared to the CDMP list in the same primary care population group. As well, the Fortin list seemed conceptually better suited for measuring multimorbidity in primary care. It reflected disease categories rather than single conditions and was more sensitive to capturing the full breadth of multimorbidity across the ages when compared to the CDMP list. Moreover, the Fortin list of conditions also covered all of the noncommunicable diseases listed in the global burden of disease list for leading causes of disability-adjusted life year in Singapore (Additional file 3). On this basis, our study may lead to preferring Fortin's list for international comparative studies, but further studies will need to be conducted to confirm our tentative conclusion that it was indeed a more suitable operational definition of multimorbidity in the Singapore primary care setting.

\section{Strengths and limitations}

The main limitation of the current study was that the prevalence rates reported may be underestimated for the following reasons. Firstly, the study only provided a snapshot over a one-year period. Secondly, there may be under-reporting of chronic conditions in the electronic medical records especially for patients who seek treatment outside the polyclinics who may not have their other medical conditions recorded in the electronic medical records within the polyclinic system. Thirdly, mental health conditions were probably under-reported as we found that the prevalence was very low [27].

The major strength of the study was the rigorous mapping of ICD-10 diagnostic codes available in the primary care EMR to two multimorbidity lists (CDMP and Fortin) with two operational definitions of multimorbidity (MM2+ and MM3+).

\section{Conclusions}

In conclusion, this is the first study describing the prevalence of multimorbidity using a large electronic medical record database in a Singapore primary care setting. We compared the prevalence of multimorbidity using two different lists of chronic conditions to measure multimorbidity. The crude prevalence rate of multimorbidity with a cut-off threshold of three conditions was 23.7 and $17.7 \%$ based on Fortin list and CDMP list respectively. The standardised prevalence rate was $17.2 \%$ (CI 17.2, $17.3)$ and $12.4 \%$ (CI 12.3, 12.5) based on Fortin list and CDMP list respectively. We determined that the prevalence rate of multimorbidity increased with age and that males had higher prevalence rate of multimorbidity compared to females. We also reported differences in the standardised prevalence rates of multimorbidity between the different ethnic groups.

We propose using three or more chronic conditions for defining multimorbidity as the higher cut-off threshold identified a smaller number of patients with higher needs compared to using two or more chronic 
conditions. Our study results also leaned towards using Fortin's list as it was more sensitive to capturing the full breadth of multimorbidity across the ages when compared to the CDMP list in the primary care setting in Singapore.

\section{Abbreviations}

ASE SPR: Age-stratified, sex-and-ethnicity standardized prevalence rate; CDMP: Chronic Disease Management Programme; Cl: Confidence interval; COPD: Chronic obstructive pulmonary disease; CPR: Crude prevalence rate; EAS SPR: Ethnicity-stratified, age-and-sex standardized prevalence rate; MM: Multimorbidity; MM2+: Definition of multimorbidity as having 2 or more chronic conditions; MM3+: Definition of multimorbidity as having 3 or more chronic conditions; CDMP MM2+: Operational definition of multimorbidity as having 2 or more chronic conditions according to the CDMP list of chronic conditions; CDMP MM3+: Operational definition of multimorbidity as having 3 or more chronic conditions according to the CDMP list of chronic conditions; Fortin MM2+: Operational definition of multimorbidity as having 2 or more chronic conditions according to the list of chronic conditions in Fortin et al.; Fortin MM3+: Operational definition of multimorbidity as having 3 or more chronic conditions according to the list of chronic conditions in Fortin et al.; ICD-10: International Classification of Diseases, Tenth Revision; ICPC-2: International Classification of Primary Care, Second edition; MOH: Ministry of Health of Singapore; NHGP: National Healthcare Group Polyclinics; SAE SPR: Sex-stratified, age-and-ethnicity standardized prevalence rate; SD: Standard deviation

\section{Supplementary Information}

The online version contains supplementary material available at https://doi. org/10.1186/s12889-021-11464-7.

Additional file 1. CDMP List of Conditions.

Additional file 2. Fortin List of Conditions.

Additional file 3. Global Burden of Disease List vs Fortin List of Conditions.

\section{Acknowledgements}

The authors would like to thank Mr. Jeremy Lew for helping with proofreading and editing the manuscript.

\section{Authors' contributions}

ESL, BLR, MF and MS conceptualised and designed the study. YX extracted and analysed the data. ESL and PSSL led the manuscript writing with inputs from YX, BLR, MF and MS. All authors read and approved the final manuscript. The corresponding author attests that all listed authors meet the authorship criteria and that no others meeting the criteria have been omitted.

\section{Funding}

This research is supported by the Singapore Ministry of Health's National Medical Research Council under the Centre Grant Programme (Ref No: NMRC/CG/C019/2017). The researchers were independent from the funding source. The funders had no role in the design and conduct of the study; the collection, analysis and interpretation of the data; the preparation of the manuscript; or the decision to submit the manuscript for publication.

\section{Availability of data and materials}

The dataset and personal health data generated and/or analysed during the current study are not publicly available due to the Data Protection Act Commission Singapore - Advisory Guidelines for the Healthcare Sector and legal and ethical restrictions related to data privacy protection but are available from the corresponding author on reasonable request.

\section{Declarations}

\section{Ethics approval and consent to participate}

The study was granted ethics approval by the National Healthcare Group Domain Specific Review Board (Reference: 2018/00466). Due to the retrospective nature of the study and large number of de-identified electronic medical records, waiver of consent was obtained and approved for this study.

\section{Consent for publication}

Not applicable.

\section{Competing interests}

The authors declare that they have no competing interests.

\section{Author details}

${ }^{1}$ Clinical Research Unit, National Healthcare Group Polyclinics, Singapore, Singapore. ${ }^{2}$ Department of Epidemiology and Biostatistics, Schulich School of Medicine \& Dentistry, Western University, 1151 Richmond St, London, ON N6A 5C1, Canada. ${ }^{3}$ Centre for Studies in Family Medicine, Department of Family Medicine, Schulich School of Medicine \& Dentistry, Western University, 1151 Richmond St, London, ON N6A 5C1, Canada. ${ }^{4}$ Department of Family Medicine, Centre de Santé et de Services Sociaux de Chicoutimi, Unité de médecine de famille, University of Sherbrooke, 305, rue St-Vallier, Chicoutimi, QC G7H 5H6, Canada.

Received: 11 November 2020 Accepted: 7 July 2021

Published online: 16 July 2021

\section{References}

1. Ageing and health. https://www.who.int/news-room/fact-sheets/detail/a geing-and-health. Accessed 8 Nov 2020.

2. Violan C, Foguet-Boreu Q, Flores-Mateo G, Salisbury C, Blom J, Freitag M, et al. Prevalence, determinants and patterns of multimorbidity in primary care: a systematic review of observational studies. PLoS One. 2014;9(7): e102149. https://doi.org/10.1371/journal.pone.0102149.

3. Fortin M, Stewart M, Poitras ME, Almirall J, Maddocks H. A systematic review of prevalence studies on multimorbidity: toward a more uniform methodology. Ann Fam Med. 2012;10(2):142-51. https://doi.org/10.1370/a fm.1337.

4. Fortin M, Hudon C, Haggerty J, Akker M, Almirall J. Prevalence estimates of multimorbidity: a comparative study of two sources. BMC Health Serv Res. 2010;10(1):111. https://doi.org/10.1186/1472-6963-10-111.

5. Boyd CM, Fortin M. Future of multimorbidity research: how should understanding of multimorbidity inform health system design? Public Health Rev. 2010;32(2):451-74. https://doi.org/10.1007/BF03391611.

6. Lee YAJ, Xie Y, Lee PSS, Lee ES. Comparing the prevalence of multimorbidity using different operational definitions in primary care in Singapore based on a cross-sectional study using retrospective, large administrative data. BMJ Open. 2020;10(12):e039440. https://doi.org/10.1136/ bmjopen-2020-039440.

7. Willadsen TG, Bebe A, Koster-Rasmussen R, Jarbol DE, Guassora AD, Waldorff $F B$, et al. The role of diseases, risk factors and symptoms in the definition of multimorbidity - a systematic review. Scand J Prim Health Care. 2016;34(2): 112-21. https://doi.org/10.3109/02813432.2016.1153242.

8. Fortin M, Almirall J, Nicholson K. Development of a research tool to document self-reported chronic conditions in primary care. J Comorb. 2017; 7(1):117-23. https://doi.org/10.15256/joc.2017.7.122.

9. Chronic Disease Management Programme Handbook for Healthcare Professionals. https:/www.primarycarepages.sg/Documents/Practice\%20Ma nagement/CDMP\%2OHandbook\%20for\%20Healthcare\%20Professionals\%202 018.pdf. Accessed 8 Nov 2020.

10. The World Health Report 2008. Primary Care - Now more than ever. https:// www.who.int/whr/2008/whr08_en.pdf. Accessed 8 Nov 2020.

11. Primary Healthcare Services. https://www.moh.gov.sg/our-healthcaresystem/healthcare-services-and-facilities/primary-healthcare-services. Accessed 8 Nov 2020.

12. O'Halloran J, Miller GC, Britt H. Defining chronic conditions for primary care with ICPC-2. Fam Pract. 2004:21(4):381-6. https://doi.org/10.1093/fampra/ cmh407. 
13. Standardization of rates- Report from the Association of Public Health Epidemiologists in Ontario (APHEO) through the Core Indicators for Public Health in Ontario Project. http://core.apheo.ca/index.php?pid=193. Accessed 8 Nov 2020.

14. Population Trends, 2016 - Table A1.3 Singapore residents by age group, ethnic group and sex. https://www.singstat.gov.sg/-/media/files/publica tions/population/population2016.pdf. Accessed 8 Nov 2020.

15. Feely A, Lix LM, Reimer K. Estimating multimorbidity prevalence with the Canadian chronic disease surveillance system. Health Promot Chronic Dis Prev Can. 2017;37(7):215-22. https://doi.org/10.24095/hpcdp.37.7.02.

16. Subramaniam M, Abdin E, Picco L, Vaingankar JA, Chong SA. Multiple chronic medical conditions: prevalence and risk factors--results from the Singapore mental health study. Gen Hosp Psychiatry. 2014;36(4):375-81. https://doi.org/10.1016/j.genhosppsych.2014.03.002.

17. Picco L, Achilla E, Abdin E, Chong SA, Vaingankar JA, McCrone P, et al. Economic burden of multimorbidity among older adults: impact on healthcare and societal costs. BMC Health Serv Res. 2016;16(1):173. https:/ doi.org/10.1186/s12913-016-1421-7.

18. Ge L, Yap CW, Heng BH. Sex differences in associations between multimorbidity and physical function domains among community-dwelling adults in Singapore. PLoS One. 2018;13(5):e0197443. https://doi.org/10.1371/ journal.pone.0197443.

19. Quah JHM, Wang P, Ng RRG, Luo N, Tan NC. Health-related quality of life of older Asian patients with multimorbidity in primary care in a developed nation. Geriatr Gerontol Int. 2017;17(10):1429-37. https://doi.org/10.1111/ ggi.12881.

20. Ge L, Ong R, Yap CW, Heng BH. Effects of chronic diseases on health-related quality of life and self-rated health among three adult age groups. Nurs Health Sci. 2019;21(2):214-22. https://doi.org/10.1111/nhs.12585.

21. Low LL, Kwan YH, Ko MSM, Yeam CT, Lee VSY, Tan WB, et al. Epidemiologic characteristics of multimorbidity and Sociodemographic factors associated with multimorbidity in a rapidly aging Asian country. JAMA Netw Open. 2019;2(11):e1915245. https://doi.org/10.1001/jamanetworkopen.2019.15245.

22. Wu CS, Lai MS, Gau SS, Wang SC, Tsai HJ. Concordance between patient self-reports and claims data on clinical diagnoses, medication use, and health system utilization in Taiwan. PLoS One. 2014;9(12):e112257. https:// doi.org/10.1371/journal.pone.0112257.

23. Jiang L, Zhang B, Smith ML, Lorden AL, Radcliff TA, Lorig K, et al. Concordance between self-reports and Medicare claims among participants in a National Study of chronic disease self-management program. Front Public Health. 2015;3:222.

24. Schafer I, Hansen H, Schon G, Hofels S, Altiner A, Dahlhaus A, et al. The influence of age, gender and socio-economic status on multimorbidity patterns in primary care. First results from the multicare cohort study. BMC Health Serv Res. 2012;12(1):89. https://doi.org/10.1186/1472-6963-12-89.

25. Ryan BL, Bray Jenkyn K, Shariff SZ, Allen B, Glazier RH, Zwarenstein M, et al. Beyond the grey tsunami: a cross-sectional population-based study ofmultimorbidity in Ontario. Can J Public Health. 2018;109(5-6):845-54. https://doi.org/10.17269/s41997-018-0103-0.

26. Prazeres F, Santiago L. Prevalence of multimorbidity in the adult population attending primary care in Portugal: a cross-sectional study. BMJ Open. 2015; 5(9):e009287. https://doi.org/10.1136/bmjopen-2015-009287.

27. Chong SA, Abdin E, Vaingankar JA, Kwok KW, Subramaniam M. Where do people with mental disorders in Singapore go to for help? Ann Acad Med Singap. 2012;41(4):154-60.

\section{Publisher's Note}

Springer Nature remains neutral with regard to jurisdictional claims in published maps and institutional affiliations.

Ready to submit your research? Choose BMC and benefit from:

- fast, convenient online submission

- thorough peer review by experienced researchers in your field

- rapid publication on acceptance

- support for research data, including large and complex data types

- gold Open Access which fosters wider collaboration and increased citations

- maximum visibility for your research: over $100 \mathrm{M}$ website views per year

At BMC, research is always in progress.

Learn more biomedcentral.com/submissions 